\title{
Endovascular treatment of renal artery pseudoaneurysm arising from the previously implanted renal artery stent
}

\author{
Mehmet Çelik', Barkın Kültürsay' ${ }^{1}$ Ayhan Küp', Yusuf Yılmaz², Ahmet Karaduman'1, Gökhan Alıcı' \\ 'Department of Cardiology, Kartal Koşuyolu Education and Research Hospital, Istanbul, Turkey \\ 2Department of Cardiology, Istanbul Medeniyet University Faculty of Medicine, Istanbul, Turkey
}

\author{
Correspondence to: \\ Barkın Kültürsay, MD, \\ Kartal Koşuyolu Yüksek İhtisas \\ Eğitim ve Araştırma Hastanesi, \\ Denizer caddesi Cevizli Kavşağı \\ No. 2 , \\ Kartal, İstanbul, Turkey, \\ phone: +905546383037 , \\ e-mail: bkultursay@gmail.com \\ Copyright by the Author(s), 2021 \\ Kardiol Pol. 2021; \\ 79 (12): 1391-1392; \\ DOI: $10.33963 /$ KP.a2021.0153 \\ Received: \\ August 8, 2021 \\ Revision accepted: \\ October 29, 2021 \\ Published online: \\ November 3, 2021
}

Renal artery pseudoaneurysm is a rare vascular complication related to percutaneous procedures, renal biopsy, nephrectomy, penetrating traumas, and more rarely blunt traumas [1]. It can present with palpable abdominal mass, flank and lower back pain, renal infarction, hematuria, and even death [2]. Sometimes, it is incidentally found during diagnostic procedures, such as abdominopelvic computed tomography or conventional angiography. In this case, we have a different predisposing factor for renal artery pseudoaneurysm: a renal artery stent. Herein we aim to present a case of isolated renal artery pseudoaneurysm that developed after renal artery stenting.

A 65-year-old male patient with a history of renal artery stent implantation $(7.0 \times 12 \mathrm{~mm}$ Carbofilm coated Radix 2 stent [CID S.P.A]) due to left renal artery stenosis (Supplementary material, Video S1, S2) was referred to our department due to macroscopic hematuria. In the past medical history, there was no abnormality except right kidney atrophy and stenting of the left renal artery 3 years earlier. He had no recent history of intravenous contrast exposure or nephrotoxic drug use. Computed tomographic angiography was performed, and a left renal artery saccular pseudoaneurysm measuring $15 \times 11 \mathrm{~mm}$ originating from the proximal part of the stent was detected (Figure 1A).

During conventional renal angiography, it was observed that the left renal stent was open but focal dilatation of the left renal artery, originating from the proximal part of the stent in the left renal artery, attributed to pseudoaneurysm was detected (Figure 1B; Supplementary material, Video S3). Since untreated renal pseudoaneurysms are potentially life-threatening, the decision for intervention was made. Endovascular treatment is currently accepted as the firstline management of renal pseudoaneurysm in hemodynamically stable patients, as it is highly effective, safe, and unlikely to cause any long-term renal impairment [3]. Therefore, the patient underwent endovascular treatment. The pseudoaneurysm was reached with a 0.014-inch guidewire through the left renal artery stent. Corsair Pro microcatheter (ASAHI Intecc, Aichi, Japan) was advanced into the aneurysm via a guidewire. The pseudoaneurysmatic segment was occluded using 6 coils (Tornado, Cook, Bloomington, IN, USA) sizing $8 \times 15,7 \times 30,7 \times 20,6 \times 20,5 \times 10$, and $5 \times 8 \mathrm{~mm}$ (Figure 1C; Supplementary material, Video S4). After successful coil embolization, selective left renal angiography showed minimal contrast passage into the pseudoaneurysm (Supplementary material, Video S4). The patient was then discharged, and the follow-up was uneventful for 3 months. At the third month's visit, computed tomographic angiography demonstrated that the pseudoaneurysm was obliterated, and there was no contrast in the pseudoaneurysm segment (Figure 1D).

Renal artery pseudoaneurysm is a rare vascular lesion and is usually related to blunt trauma, deceleration injury, or urological interventions such as partial nephrectomy, percutaneous nephrolithotomy, renal biopsy-ureterorenoscopy for laser lithotripsy, and renal transplantation. Although these patients are clinically asymptomatic, clinical manifestations of these lesions include macroscopic hematuria, flank and lower back pain, hypertension and palpable abdominal mass [2]. 


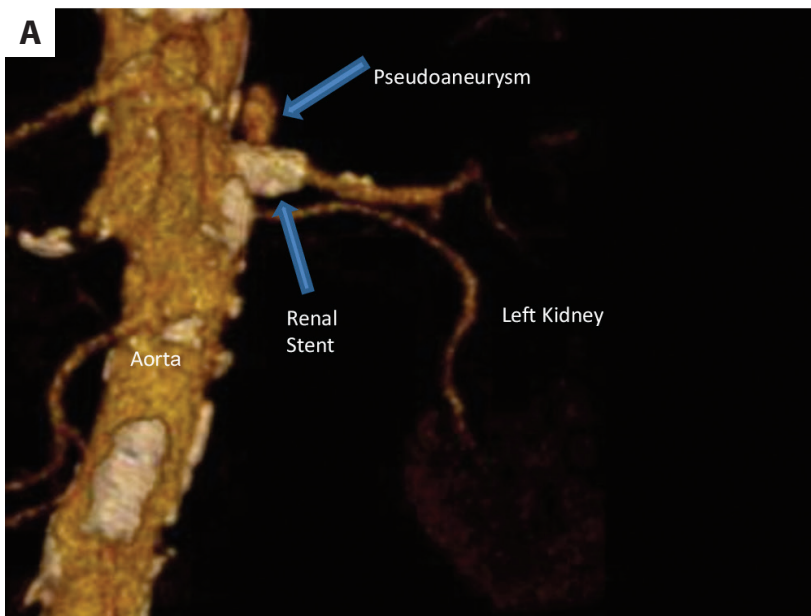

\section{B}
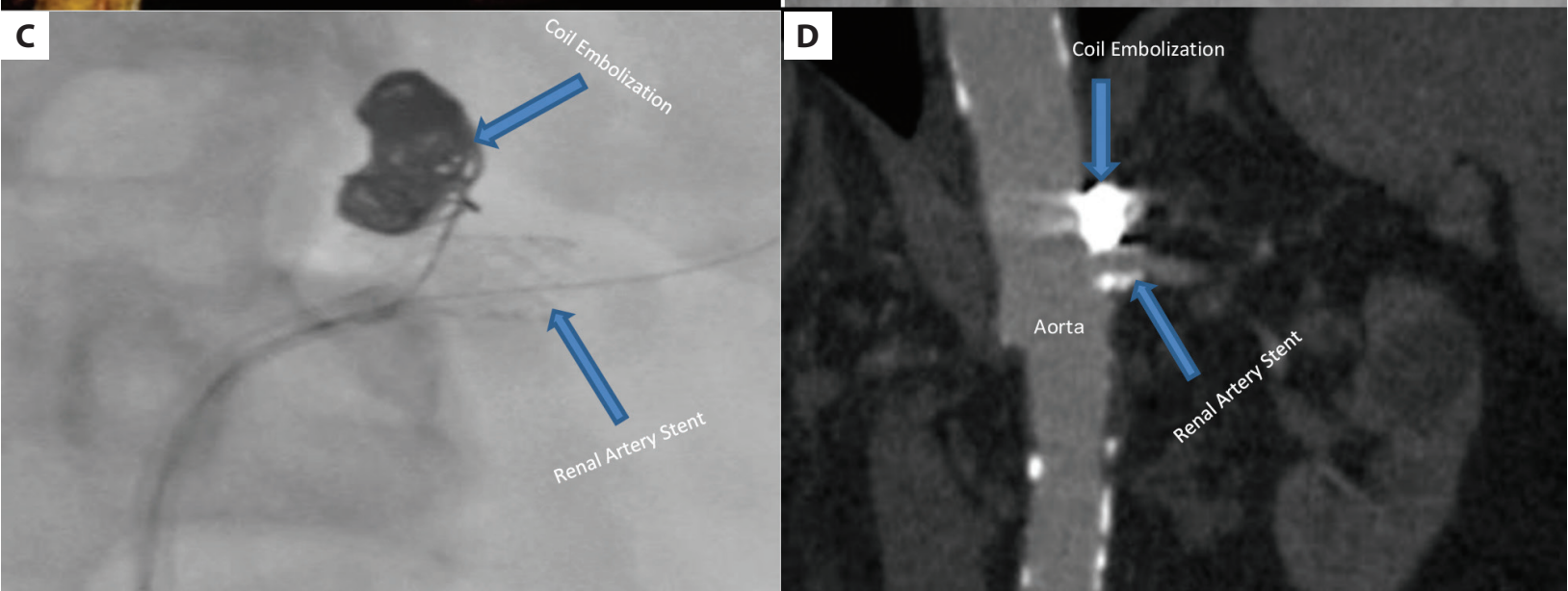

Figure 1. A. 3D computed tomographic angiography (CTA) showing pseudoaneurysm measuring approximately $15 \times 11 \mathrm{~mm}$ originating from the stent struts in the proximal portion of the left renal artery. B. Conventional selective renal angiography showing pseudoaneurysm arising from the stent struts. C. Successful percutaneous closure of the pseudoaneurysm by coil embolization. D. 2D CTA demonstrating the pseudoaneurysm is completely obliterated by coil embolization and there is no contrast passage into the pseudoaneurysm

We described a pseudoaneurysm of the renal artery that developed 3 years after renal artery stenting. Continued atherosclerotic process and hypertension following renal artery stenting may have led to the development of pseudoaneurysm. The appearance of a pseudoaneurysm has not previously been reported in the literature after renal artery stenting. Consequently, it should be kept in mind that, besides percutaneous interventions and traumas to the urinary system, pseudoaneurysm may also develop after renal artery stenting.

\section{Supplementary material}

Supplementary material is available at https://journals. viamedica.pl/kardiologia_polska.

\section{Article information}

Conflict of interest: None declared.

Open access: This article is available in open access under Creative Common Attribution-Non-Commercial-No Derivatives 4.0 Interna- tional (CC BY-NC-ND 4.0) license, allowing to download articles and share them with others as long as they credit the authors and the publisher, but without permission to change them in any way or use them commercially. For commercial use, please contact the journal office at kardiologiapolska@ptkardio.pl.

How to cite: Çelik M, Kültürsay B, Küp A, et al. Endovascular treatment of renal artery pseudoaneurysm arising from the previously implanted renal artery stent. Kardiol Pol. 2021; 79(12): 1391-1392, doi: 10.33963/KP.a2021.0153.

\section{REFERENCES}

1. Shah S, Fatima A, Shah MD, et al. Post-PCNL renal artery pseudoanurysm. J Coll Physicians Surg Pak. 2018; 28(3): 238-239, doi: 10.29271/jcpsp.2018.03.238, indexed in Pubmed: 29544585.

2. Hadjipavlou M, Abbaraju J, Serafimov V, et al. Spontaneous rupture of a renal artery pseudoaneurysm with no precipitating risk factor. JRSM Open. 2018; 9(4): 2054270418758568, doi: 10.1177/2054270418758568, indexed in Pubmed: 29707224.

3. Jubber I, Patel PR, Hori S, et al. Renal pseudoaneurysm: a rare and potentially fatal complication following ureteroscopy and laser fragmentation of stones. Ann R Coll Surg Engl. 2018; 100(3): e51-e52, doi: 10.1308/rcsann.2017.0216, indexed in Pubmed: 29364018. 